Lingua Rima: Jurnal Pendidikan Program Studi Bahasa dan Sastra Indonesia

Vol. 9 No. 1 Juli 2020

\title{
PERBEDAAN MODEL GROUP INVESTIGATION DAN MODEL SINEKTIK TERHADAP KETERAMPILAN MENULIS TEKS BERITA SISWA KELAS VIII SMP NEGERI 17 KOTA SERANG
}

\author{
Ilmi Solihat ${ }^{1}$, Erwin Salpa Riansi ${ }^{2}$, Sylvia Widyatama Fitriani ${ }^{3}$ \\ Universitas Sultan Ageng Tirtayasa \\ ilmisolihat@untirta.ac.id ${ }^{1}$ \\ salpariansierwin@untirta.ac.id ${ }^{2}$ \\ sylviawf20@gmail.com ${ }^{3}$
}

\begin{abstract}
ABSTRAK
Tujuan penelitian ini yaitu mengetahui perbedaan model Group Investigation dan model Sinektik terhadap keterampilan menulis teks berita siswa kelas VIII SMP Negeri 17 Kota Serang. Penelitian ini merupakan penelitian quasi eksperimen. Populasi penelitian ini yaitu tujuh kelas sejumlah 282 siswa. Sampel penelitian ini berjumlah 30 siswa kelas VIII F dan kelas VIII G berjumlah 30 siswa, sedangkan sampel yang digunakan dalam penelitian ini dengan menggunakan simple random sampling adalah kelas VIII F sebagai kelas yang diberi perlakuan model Group Investigation dan kelas VIII G diberi perlakuan model Sinektik. Dari hasil tersebut diperoleh, kelas VII F 30 siswa sebagai kelas eksperimen dan kelas VIII G sebagai kelas kontrol. Teknik pengumpulan data yang digunakan dalam penelitian ini adalah teknis tes, yaitu dengan menggunakan uji-t dua pihak dengan taraf signifikan $(\alpha=0,05)$. Hasil perhitungan nilai $\mathrm{t}_{\text {tabel }}$ dengan $\mathrm{dk}=\mathrm{n}_{1}+\mathrm{n}_{2}-2=30+30-2=58, \mathrm{t}_{\text {tabel }}=2,002$ dan $\mathrm{t}_{\text {hitung }}=4,89$ dengan kriteria $\mathrm{t}_{\text {tabel }}>\mathrm{t}_{\text {tabel }}>\mathrm{t}_{\text {hitung }}$ maka Ho ditolak dan jika $-\mathrm{t}_{\text {tabel }}>\mathrm{t}_{\text {tabel }}>\mathrm{t}_{\text {hitung }}$ maka Ha diterima dari hasil perhitungan yang didapatkan $-2,00<4,89<2,002$ maka sesuai dengan kriteria penguji $-t_{\text {tabel }}>t_{\text {tabel }}>t_{\text {hitung }}$ maka Ha diterima. Artinya, terdapat perbedaan dalam penerapan model pembelajaran model Group Investigation dan model Sinektik terhadap keterampilan menulis teks berita siswa kelas VIII SMP Negeri 17 Kota Serang. Hal tersebut dapat disimpulkan berdasarkan data hasil pembelajaran yang memiliki peningkatan nilai posttest dikelas penerapan model Group Investigation yang memiliki selisih 12 point dengan nilai rata-rata yang menerapkan model Group Investigation dan kelas yang menerapkan model Sinektik 90,5 > 78,6.
\end{abstract}

Kata Kunci: Group Investigation, Sinektik, Menulis

\section{A. PENDAHULUAN}

Bahasa Indonesia merupakan salah satu pelajaran yang harus diikuti oleh siswa baik dari Sekolah Dasar sampai SMA/SMK sederajat atau bahkan sampai kejenjang perguruan tinggi. Tarigan (2008: 1) berpendapat bahwa, keterampilan berbahasa memiliki empat komponen, yaitu; keterampilan menyimak, keterampilan membaca, keterampilan berbicara, dan keterampilan 
Lingua Rima: Jurnal Pendidikan Program Studi Bahasa dan Sastra Indonesia

Vol. 9 No. 1 Juli 2020

menulis. Dari empat keterampilan tersebut, menulis merupakan tingkatan tersulit untuk dipelajari siswa karena menulis merupakan proses akhir, dengan tulisan batas kepahaman siswa terhadap suatu materi dapat ternilai.

Kemampuan menulis juga sebagai tolak ukur kemampuan kebahasaan maupun luar bahasa siswa. Akan tetapi, hal tersebut bukanlah menjadi hal kompleks untuk tidak mempelajari menulis. Kegiatan menulis tidak terpisahkan dengan seluruh proses pembelajaran siswa, selama proses belajar di sekolah siswa sering diperintahkan untuk menulis. Dalam prosesnya, pelajaran menulis ini terkadang membuat siswa merasa bosan dan pada akhirnya menjadi malas untuk mengikutinya. Terlebih jika siswa dipaksakan untuk menulis sebuah karangan, itu akan menjadikan tugas berat bagi siswa. Padahal, keterampilan menulis itu tidak akan datang dengan sendirinya jika tidak dibiasakan dan jika tidak dipelajari secara berkala dan teratur.

Hal tersebut yang akan menjadi tantangan tersendiri bagi pengajar untuk mengajak siswa agar aktif dan semangat untuk menulis. Menulis sebuah teks berita merupakan salah satu materi yang berkaitan dengan pelajaran menulis.Dalam menulis sebuah teks berita siswa dituntut untuk menuliskan unsur $5 \mathrm{~W}+1 \mathrm{H}$. Materi mengenai teks berita ini dipelajari pada jenjang SMP kelas VIII.Pada praktiknya, kemampuan menulis siswa khususnya dalam hal menulis berita masih jauh dari kata sempurna.

Tentunya siswa kesulitan dalam hal menulis untuk memasukan unsur $5 \mathrm{~W}+1 \mathrm{H}$ tersebut ke dalam teks berita yang mereka buat.Untuk itu, guru sebagai fasilitator harus berinovasi untuk mencari media maupun model yang mampu memotivasi siswa dalam hal keterampilan menulis teks berita ini. Guru harus mampu memecahkan permasalahan yang dihadapi siswa. Guru dituntut untuk mengupayakan agar siswa mampu menulis teks berita dengan memasukan unsurunsur yang seharusnya ada dalam teks berita.

Namun pada kenyataannya minat dan motivasi siswa masih kurang tergali dalam hal menulis. Hasil pembelajaran Bahasa Indonesia belum optimal khususnya dalam keterampilan menulis teks berita, hal ini ditunjukan dengan tidak semua siswa dapat melakukan bahkan siswa masih kebingungan ketika menulis atau mengarang karena tidak tahu apa yang harus mereka tuangkan.

Permasalahan tersebut terjadi pada siswa kelas VIII SMP Negeri 17 Kota Serang, besadarkan observasi yang dilakukan peneliti siswa di sini masih kurang termotivasi untuk menulis. Pemicu kurang berhasilnya pembelajaran menulis di sekolah ini, karena selama ini 
Lingua Rima: Jurnal Pendidikan Program Studi Bahasa dan Sastra Indonesia

Vol. 9 No. 1 Juli 2020

pengajaran Bahasa Indonesia cenderung konvensional yaitu bersifat hafalan, teoritis, serta tidak mengacu terhadap upaya mengembangkan kemampuan siswa. Kurangnya penggunaan media dalam pembelajaran menulis dan seringkali metode ceramah menjadi pilihan utama untuk mengajarkan materi.

Cara dapat dilakukan untuk mengatasi masalah keterampilan menulis siswa agar lebih optimal adalah dengan penggunaan media dalam proses belajar mengajar. Mengingat selama ini pembelajaran menulis di SMP Negeri 17 Kota Serang masih kurang dalam melibatkan penggunaan media dalam pembelajaran menulis khususnya menulis teks berita siswa akan lebih termotivasi dan terciptanya pembelajaran yang menyenangkan. Dengan adanya model pembelajaran Group Investigation dan model Sinektik diharapkan guru dan siswa lebih termotivasi untuk berkembang, lebih aktif dalam kegiatan KBM, baik secara individual maupun kelompok, dan mampu mengorganisasikan berbagai konsep serta pengalaman belajar yang mampu merangsang siswa untuk dapat mengikuti pembelajaran dengan penuh motivasi dan tingkat partisipasi yang tinggi, disamping pengetahuan dan kemampuan yang dimiliki siswa.

\section{B. KAJIAN PUSTAKA}

Menulis merupakan pengungkapan ide, pikiran, gagasan, pengetahuan dan wawasan ke dalam tulisan yang sistematis dan bisa dipahami oleh orang lain. Selaras dengan pendapat Amitaningsih (2011:76) bahwa menulis adalah kemampuan seseorang dalam melukiskan tanda kebahasaan untuk mengungkapkan gagasan atau pesan dan menyampaikan melalui bahasa tulis kepada pembaca. Keterampilan menulis juga diartikan sebagai suatu keterampilan berbahasa yang digunakan untuk berkomunikasi secara tidak langsung, tidak secara tatap muka dengan orang lain. Menulis adalah suatu proses menghasilkan tulisan yang berisi gagasan dan termasuk kegiatan yang produktif dan ekspresif.

Di dalam kegiatan menulis, seseorang itu haruslah terampil memanfaatkan struktural bahasa dan kosa kata, agar terciptanya tulisan yang menarik. Menurut Tarigan (2008: 23), keterampilan ini tidak datang secara otomatis, melainkan harus melalui latihan dan praktik yang banyak dan teratur. Oleh karena itu, dalam pembelajaran di sekolah menulis merupakan salah satu keterampilan berbahasa yang harus diajarkan kepada pelajar. Standar Kompetens mata pembelajaran Bahasa dan Sastra Indonesia SMP/MTs kelas VIII untuk menulis menyebutkan bahwa siswa diharapkan mampu mengungkapkan pikiran, perasaan, dan gagasan dalam berbagai bentuk tulisan, dengan menulis teks berita. 
Lingua Rima: Jurnal Pendidikan Program Studi Bahasa dan Sastra Indonesia

Vol. 9 No. 1 Juli 2020

Menurut Joyce (dalam Sutikno, 2016:224) bahwa model pembelajaran sinektik bertujuan untuk mengembangkan kreativitas peserta didik melalui analogi langsung dan analogi personal yang diharapkan mendorong peserta didik untuk terlibat aktif dalam tindakan kreatif. Model sinektik termasuk model pembelajaran yang membuat peserta didik berpikir kreatif sedangkan model simulasi termasuk model pembelajaran yang membuat peserta didik bisa menirukan yang di peragakan secara langsung (Krisbiono, Supriyanto, dan Rustono, 2015:126).

Group Investigation merupakan salah satu bentuk model pembelajran kooperatif yang menekankan pada partisipasi dan aktivitas siswa untuk mencari sendiri materi (informasi) pelajaran yang akan dipelajari melalui bahan-bahan yang tersedia, missalnya dari buku atau dari internet. Siswa dilibatkan sejak perencanaan, baik dalam menentukan topik maupun cara untuk mempelajarinya melalui investigasi. Tipe ini menuntut para siswa untuk memiliki kemampuan yang baik dalam berkomunikasi maupun dalam ketrampilan proses kelompok. Model Group Investigation dapat melatih siswa untuk menumbuhkan kemampuan berfikir mandiri. Keterlibatan siswa secara aktif dapat terlihat melalui tahap pertama sampai akhir pembelajaran. Adapun pengertian Group Investigation menurut Rusman (dalam Maryatun dan Desi 2019:10)

\section{METODE PENELITIAN}

Pada penelitian ini, menggunakan penelitian eksperimen. Populasi penelitian ini yaitu tujuh kelas sejumlah 282 siswa. Sampel penelitian ini berjumlah 30 siswa kelas VIII F dan kelas VIII $\mathrm{G}$ berjumlah 30 siswa, sedangkan sampel yang digunakan dalam penelitian ini dengan menggunakan simple random sampling. Pada kelas VIII F sebagai kelas yang diberi perlakuan model Group Investigation sebagai kelas ekspreimen 1 dan kelas VIII G diberi perlakuan model Sinektik sebagai kelas eksperimen 2.

Teknik pengumpulan data pada penelitian ini yaitu menggunakan tes. Tes yang digunakan yaitu berupa essay. Instrumen penilaian tes essay dalam penelitian ini yaitu dengan menilai aspek-aspek penulisan berita yaitu $5 \mathrm{~W}+1 \mathrm{H}$, gaya penulisan, keaktualan, dan kemenarikan judul. Teknik data yang digunakan dalam penelitian ini yaitu analisis statistik deskriptif dan statistik inferensial. Analisis statistik deskriptif meliputi penyajian data (tabel distribusi, histogram, poligon dan ogive), pemusatan data (mean, median dan modus) dan variasi kelompok ( rentang data, standar deviasi atau simpangan baku, dan varians). Sedangkan statistik inferensial meliputi uji normalitas, uji homogenitas dan uji t. 
Lingua Rima: Jurnal Pendidikan Program Studi Bahasa dan Sastra Indonesia

Vol. 9 No. 1 Juli 2020

\section{PEMBAHASAN}

Penelitian ini dilakukan di kelas VIII F dan VIII G SMP Negeri 17 Kota Serang dengan tujuan untuk mengetahui pengaruh dan perbedaan hasil pembelajaran menulis teks berita dengan menggunakan model Group Investigation dan model Sinektik. Hasil penelitian ini diperoleh dari hasil pretest dan posttest. Hasil pretest diperoleh dari kegiatan siswa menulis teks berita dengan tidak diberi perlakuan (model Group Investigation dan model Sinektik). Hasil posttestdiperoleh dari kegiatan siswa menulis teks berita yang telah diberi perlakuan (model Group Investigation dan model Sinektik). Model pembelajaran yang digunakan pada kelas VIII F atau kelas eksperimen adalah model Group Investigation dan kelas VIII G atau kelas kontrol adalah model Sinektik.

Pelaksanaan pembelajaran pada kelas eksperimen yang diberikan perlakuan model Group Investigation dilakukan dengan delapan tahap. Pertama, guru penyampaikan tujuan pembelajaran yang ingin dicapai pada pembelajaran dan memotivasi siswa dalam pembelajaran menulis teks berita. Kedua, guru memandu siswa untuk memilih subtopik dalam suatu topik berita dengan tujuan agar siswa ikut terlibat secara aktif pada awal proses pembelajaran. Ketiga, guru menjelaskan kepada siswa bagaimana caranya membentuk kelompok dan memandunya sesuai dengan ketentuan yang ada.Masing-masing kelompok beranggotakan 3 - 4 orang, dan kemudian guru membagikan lembar kerja siswa ke masing-masing kelompok sebagai acuan siswa dalam melaksanakan investigasi sesuai dengan subtopik yang telah mereka pilih.

Keempat, perencanaan kerja sama, dimana guru dan siswa merencanakan berbagai prosedur dalam menulis teks berita dengan memperhatikan lima aspek yaitu judul, kelengkapan isi $(5 \mathrm{~W}+1 \mathrm{H})$, penggunaan EBI yang benar, organisasi penulisan, dan kerapihan penulisan dengan menggunakan model investigasi. Kelima, siswa melaksanakan rencana investigasi dengan menggunakan sumber-sumber belajar seperti buku pakat dan teks berita yang sudah disediakan.Keenam, siswa membuat analisis dan sintesis dari berbagai macam informasi yang telah diperoleh pada tahap investigasi.Ketujuh, perwakilan kelompok menyajikan hasil investigasi. Terakhir, guru dan siswa melakukan evaluasi secara keseluruhan dari proses awal hingga akhir kegiatan berlangsung.

Tabel 4.1 Jadwal Kegiatan Penelitian

\begin{tabular}{|c|c|c|}
\hline No. & Hari/Tanggal & Kegiatan \\
\hline 1. & Rabu, 21 November 2018 & Pertemuan pertama kelas VIII Gcontrol \\
\hline
\end{tabular}




\begin{tabular}{|c|c|c|}
\hline & & $\begin{array}{l}\text { - Menjelaskan materi teks berita } \\
\text { - Memberikan pretest } \\
\text { - Evaluasi menulis teks berita }\end{array}$ \\
\hline 2. & $\begin{array}{l}\text { Kamis, } 22 \text { November } \\
2018\end{array}$ & $\begin{array}{l}\text { Pertemuan pertama kelas VIII F eksperimen } \\
\text { - Menjelaskan materi teks berita } \\
\text { - Memberikan pretest } \\
\text { - Evaluasi menulis teks berita }\end{array}$ \\
\hline 3. & $\begin{array}{c}\text { Sabtu, } 24 \text { November } \\
2018\end{array}$ & $\begin{array}{l}\text { Pertemuan pertama kelas VIII G control } \\
\text { - Memberikan posttest } \\
\text { - Evaluasi kegiatan }\end{array}$ \\
\hline & & $\begin{array}{l}\text { Pertemuan pertama kelas VIII F eksperimen } \\
\text { - Memberikan posttest } \\
\text { - Evaluasi kegiatan }\end{array}$ \\
\hline
\end{tabular}

\subsection{Deskripsi Data}

\subsubsection{Deskripsi data Pretest}

\subsubsection{Data Hasil Pretest Kelas Eksperimen (Model Pembelajaran Group Investigation)}

Jumlah siswa yang dijadikan sampel dalam kelas eksperimen sebanyak 30 orang siswa dengan skor rata-rata $=70,267$, simpangan baku $=21,78$, nilai minimum $=52$ dan nilai maksimum $=84$. Secara lebih lengkap dapat dicermati pada tabel di bawah ini.

Tabel 4.2 Distribusi Frekuensi Pretest Kelas Eksperimen

\begin{tabular}{|c|c|c|c|c|c|}
\hline \multirow{2}{*}{ No } & Kelas & Titik & \multicolumn{3}{|c|}{ Frekuensi } \\
\cline { 4 - 6 } & Interval & Tengah & Absolut & Relatif (\%) & Kumulatif (\%) \\
\hline 1 & $52-56$ & 54 & 1 & 3,33 & 0 \\
\hline 2 & $57-61$ & 59 & 0 & 0 & 3,33 \\
\hline 3 & $62-66$ & 64 & 12 & 40 & 3,33 \\
\hline 4 & $67-71$ & 69 & 4 & 13,33 & 43,33 \\
\hline
\end{tabular}


Lingua Rima: Jurnal Pendidikan Program Studi Bahasa dan Sastra Indonesia

Vol. 9 No. 1 Juli 2020

\begin{tabular}{|c|c|c|c|c|c|}
5 & $72-76$ & 74 & 5 & 16,67 & 56,66 \\
\hline 6 & $77-81$ & 79 & 8 & 26,67 & 73,33 \\
\hline & Jumlah & & $\mathbf{3 0}$ & $\mathbf{1 0 0}$ & $\mathbf{1 0 0}$ \\
\hline
\end{tabular}

\subsubsection{Data Hasil Pretest Kelas Kontrol (Model Pembelajaran Sinektik)}

Jumlah siswa yang dijadikan sampel dalam kelas kontrol sebanyak 30 orang siswa dengan skor rata-rata $=58,4$, simpangan baku $=5,18$, nilai minimum $=44$ dan nilai maksimum $=76$. Secara lebih lengkap dapat dicermati pada tabel di bawah ini.

Tabel 4.3Distribusi FrekuensiPretest Kelas Kontrol

\begin{tabular}{|c|c|c|c|c|c|}
\hline \multirow{2}{*}{ No } & \multirow{2}{*}{$\begin{array}{c}\text { Kelas } \\
\text { Interval }\end{array}$} & Titik & \multicolumn{4}{|c|}{ Frekuensi } \\
\cline { 5 - 6 } & Tengah & Absolut & Relatif (\%) & Kumulatif (\%) \\
\hline 1 & $44-48$ & 46 & 5 & 16,67 & 0 \\
\hline 2 & $49-53$ & 51 & 2 & 6,67 & 16,67 \\
\hline 3 & $54-58$ & 56 & 7 & 23,33 & 23,34 \\
\hline 4 & $59-63$ & 61 & 8 & 26,66 & 46,66 \\
\hline 5 & $64-68$ & 66 & 6 & 20 & 73,33 \\
\hline 6 & $69-73$ & 71 & 2 & 6,67 & 93,33 \\
\hline & Jumlah & & $\mathbf{3 0}$ & $\mathbf{1 0 0}$ & $\mathbf{1 0 0}$ \\
\hline
\end{tabular}

\subsubsection{Deskripsi Data Posttest}

\subsubsection{Data Hasil Posttest Kelas Eksperimen Menggunakan Model Group Investigation}

Posttest dilakukan untuk melihat pencapaian setelah treatment dengan menggunakan model Group Investigation. Bentuk Posttestsama dengan pretest yaitu menulis teks berita. Jumlah siswa yang dijadikan sampel dalam kelas kontrol sebanyak 30 orang siswa dengan skor rata-rata $=90,53$, simpangan baku $=6,10$, nilai minimum $=80$ dan nilai maksimum $=$ 100. Secara lebih lengkap dapat dicermati pada tabel di bawah ini.

Tabel 4.4 Distribusi Frekuensi Posttest Kelas Eksperimen

\begin{tabular}{|l|l|l|l|}
\hline No & Kelas & Titik & Frekuensi \\
\hline
\end{tabular}


Lingua Rima: Jurnal Pendidikan Program Studi Bahasa dan Sastra Indonesia

\begin{tabular}{|c|c|c|c|c|c|}
\hline & Interval & Tengah & Absolut & Relatif (\%) & Kumulatif (\%) \\
\hline 1 & $80-83$ & 81.5 & 2 & 6,67 & 0 \\
\hline 2 & $84-86$ & 85 & 6 & 20 & 6,67 \\
\hline 3 & $87-89$ & 88 & 5 & 16,67 & 26,67 \\
\hline 4 & $90-92$ & 91 & 8 & 26,66 & 43,34 \\
\hline 5 & $93-95$ & 94 & 0 & 0 & 70 \\
\hline 6 & $96-100$ & 98 & 9 & 30 & 70 \\
\hline & Jumlah & & $\mathbf{3 0}$ & $\mathbf{1 0 0}$ & $\mathbf{1 0 0}$ \\
\hline
\end{tabular}

\subsubsection{Data Hasil Posttest Kelas Kontrol Menggunakan Model Sinektik}

Jumlah siswa yang dijadikan sampel dalam kelas eksperimen sebanyak 30 orang siswa dengan skor rata-rata $=78,67$, simpangan baku $=10,97$ nilai minimum $=64$ dan nilai maksimum $=100$. Secara lebih lengkap dapat dicermati pada tabel di bawah ini.

Tabel 4.5 Distribusi Frekuensi Posttest Kelas Kontrol

\begin{tabular}{|c|c|c|c|c|c|}
\hline \multirow{2}{*}{ No } & Kelas & Titik & \multicolumn{3}{|c|}{ Frekuensi } \\
\cline { 4 - 6 } & Interval & Tengah & Absolut & Relatif (\%) & Kumulatif (\%) \\
\hline 1 & $64-69$ & 66,5 & 9 & 30 & 0 \\
\hline 2 & $70-75$ & 72,5 & 4 & 13,33 & 30 \\
\hline 3 & $76-81$ & 78,5 & 7 & 23,33 & 43,33 \\
\hline 4 & $82-87$ & 84,5 & 1 & 3,34 & 66,66 \\
\hline 5 & $88-94$ & 91,5 & 6 & 20 & 70 \\
\hline 6 & $95-100$ & 97,5 & 3 & 10 & 90 \\
\hline & Jumlah & & $\mathbf{3 0}$ & $\mathbf{1 0 0}$ & $\mathbf{1 0 0}$ \\
\hline
\end{tabular}

\subsubsection{Perbedaan Hasil Penelitian antara Pretest dan Postest Kelas Eksperimen dan Kelas Kontrol}

Setelah dilakukan dua tahap penelitian, yaitu pretest, posttest dan analisis data yang diperoleh maka ditemukan adanya perbedaan hasil belajar siswa dalam pembelajaran 
menulis teks berita yang dilihat dari perolehan nilai rata-rata siswa kelas eksperimen dan kelas kontrol dalam menulis teks berita dapat digambarkan ke dalam diagram tabel berikut ini.

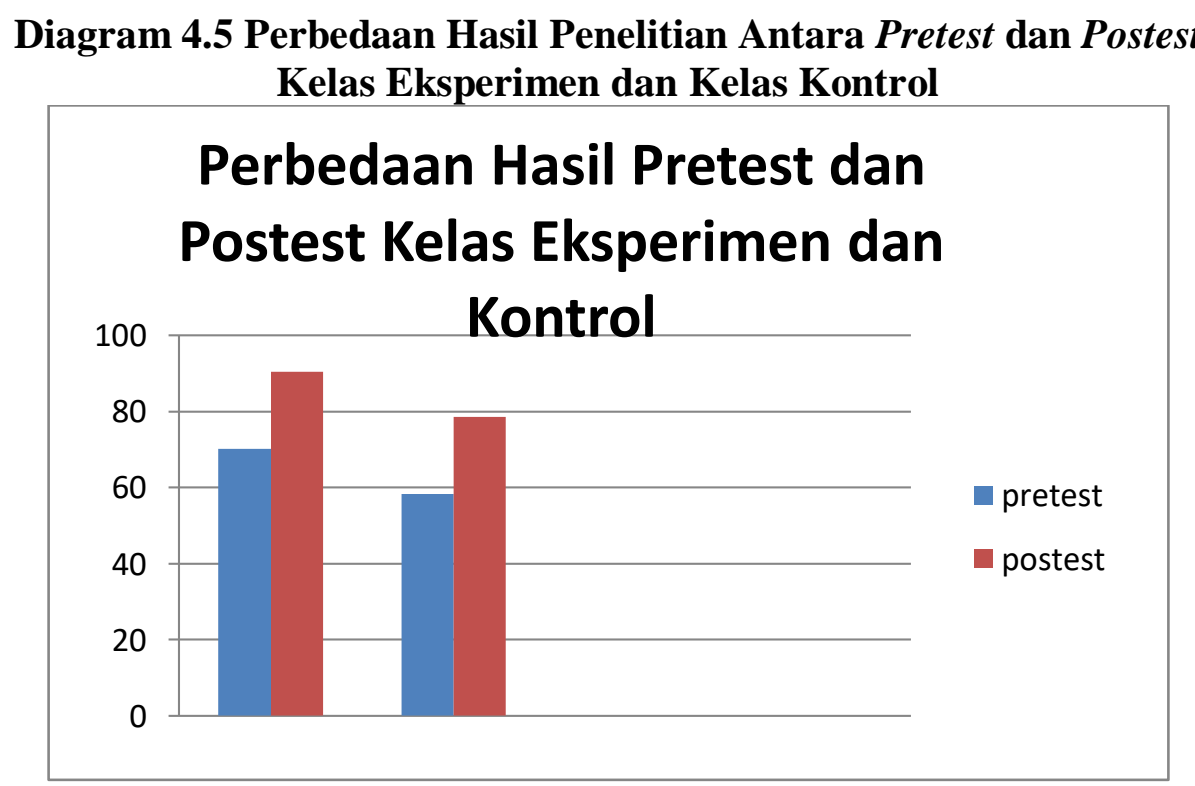

Pada gambar diagram di atas terdapat perbedaan nilai rata-rata pretest kelas eksperimen dan kelas kontrol dalam menulis teks berita. Hal ini terlihat jelas bahwa nilai rata-rata pretest atau sebelum diberikan perlakuan kelas eksperimen adalah 70,267 sedangkan nilai rata-rata pretest kelas kontrol 58,4. Selain itu, terdapat perbedaan peningkatan nilai rata-rata postest kelas eksperimen yang menggunakan model Group Investigation adalah 90,53 dan peningkatan nilai rata-rata postest kelas kontrol yang menggunakan model pengajaran langsung dalah 78,67. Berdasarkan data tersebut bahwa kelas eksperimen ataupun kontrol mengalami peningkatan. Dapat disimpulkan bahwa adanya perbedaan antara kelas eksperimen yang menggunakan model Group Investigation dan kelas kontrol yang menggunakan model 
Lingua Rima: Jurnal Pendidikan Program Studi Bahasa dan Sastra Indonesia

Vol. 9 No. 1 Juli 2020

pembelajaran sinektik. Perbedaan tersebut terlihat dalam nilai rata-rata posttest yang didapatkan oleh kelas eksperimen sebesar 90,53dan posttest kelas kontrol 78,67.

\subsection{Pengujian Persyaratan Analisis}

\subsubsection{Uji Normalitas}

\subsubsection{Uji Normalitas Data Pretest Kelas Eksperimen dan Kelas Kontrol}

Berdasarkan data hasil pretest eksperimen dan kontrol diolah dengan menggunakan statistik deskriptif untuk mencari kenormalan data dari kedua kelompok. Uji normalitas dilakukan untuk mengetahui apakah data pretest pada kelas eksperimen dan kontrol normal atau tidak normal. Digunakan uji-Chi pada taraf signifikan $5 \%(\alpha=0,05)$ untuk menguji normal atau tidak normalnya data dalam penelitian ini. Kriteria pengujian yang akan digunakan adalah:

Jika $\chi_{\text {hitung }}^{2}>\chi_{\text {tabel }}^{2}$ maka $\mathrm{H}_{\mathrm{o}}$ ditolak

Jika $\chi_{\text {hitung }}^{2}<\chi_{\text {tabel }}^{2}$ maka $\mathrm{H}_{\mathrm{o}}$ diterima

Tabel 4.6 Hasil Uji Normalitas Data Pretest Eksperimen dan Kontrol

\begin{tabular}{|l|c|c|c|c|c|}
\hline Kelompok Kelas & $\chi_{\text {hitung }}^{2}$ & Db & $\mathbf{A}$ & $\chi_{\text {tabel }}^{2}$ & Keputusan \\
\hline Eksperimen & 10,980 & 5 & \multirow{2}{*}{0,05} & \multirow{2}{*}{11,070} & Normal \\
\cline { 1 - 3 } & 6,7302 & 5 & & & Normal \\
\hline
\end{tabular}

\subsubsection{Uji Normalitas Data Posttest Kelas Eksperimen dan Kelas Kontrol}

Berdasarkan data hasil pretest eksperimen dan kontrol diolah dengan menggunakan statistik deskriptif untuk mencari kenormalan data dari kedua kelompok. Uji normalitas dilakukan untuk mengetahui apakah data pretest pada kelas eksperimen dan kontrol normal atau tidak normal. Digunakan uji-Chi pada taraf signifikan $5 \%(\alpha=0,05)$ untuk menguji normal atau tidak normalnya data dalam penelitian ini. Kriteria pengujian yang akan digunakan adalah:

Jika $\chi_{\text {hitung }}^{2}>\chi_{\text {tabel }}^{2}$ maka $\mathrm{H}_{\mathrm{o}}$ ditolak

Jika $\chi_{\text {hitung }}^{2}<\chi_{\text {tabel }}^{2}$ maka $\mathrm{H}_{\mathrm{o}}$ diterima

Tabel 4.7 Hasil Uji Normalitas Data PosttestEksperimen dan Kontrol

\begin{tabular}{|l|l|l|l|l|l|}
\hline Kelompok & $\chi^{2}$ hitung & Db & $\mathbf{A}$ & $\chi_{\text {tabel }}^{2}$ & Keputusan \\
\hline
\end{tabular}




\begin{tabular}{|l|c|c|c|c|c|}
\hline \multicolumn{1}{|c|}{ Kelas } & & & & & \\
\cline { 1 - 3 } Eksperimen & 5,607 & 5 & \multirow{2}{*}{0,05} & \multirow{2}{*}{11,070} & Normal \\
\cline { 1 - 3 } \cline { 5 - 6 } Kontrol & 4,792 & 5 & & & Normal \\
\hline
\end{tabular}

\subsubsection{Uji Homogenitas}

\subsubsection{Uji Homogenitas PretestKelas Eksperimen dan Kontrol}

Berdasarkan hasil uji normalitas diperoleh bahwa data berdistribusi normal, sehingga dilanjutkan dengan mencari kehomogenitasan data dari kedua kelompok.Uji homogenitas dilakukan untuk mengetahui apakah varians-variansdari data hasi pretes pada kelas eksperimen dan kelas kontrol homogen atau tidak homogen. Digunakan uji-F pada taraf signifikan 5\% $(a=0,05)$ untuk menguji homogen atau tidak homogen data dalam penelitian ini. Hipotesis yang akan diuji adalah:

$\mathrm{H}_{\mathrm{o}}=$ Nilai varians kedua data homogen

$\mathrm{H}_{1}=$ Nilai varians kedua data tidak homogen

Kriteria pengujian :

Jika $\mathrm{F}_{\text {hitung }}<\mathrm{F}_{\text {tabel }}$, maka $\mathrm{H}_{\mathrm{o}}$ diterima

Jika $\mathrm{F}_{\text {hitung }}>\mathrm{F}_{\text {tabel }}$, maka $\mathrm{H}_{\mathrm{o}}$ ditolak

Tabel 4.8 Hasil Uji Homogenitas Data PretestEksperimen dan Kontrol

\begin{tabular}{|l|l|l|l|l|l|l|}
\hline $\begin{array}{l}\text { Kelompok } \\
\text { Kelas }\end{array}$ & $\boldsymbol{N}$ & $\mathbf{D} \boldsymbol{\boldsymbol { S } ^ { 2 }}$ & $\boldsymbol{F}_{\text {hitung }}$ & $\boldsymbol{F}_{\text {tabel }}$ & Keputusan \\
\hline Eksperimen & 30 & 29 & 474,55 & 0,056 & 3,35 & Homogen \\
\hline
\end{tabular}

\subsubsection{Uji HomogenitasPosttestKelas Eksperimen dan Kontrol}

Berdasarkan hasil uji normalitas diperoleh bahwa data berdistribusi normal, sehingga dilanjutkan dengan mencari kehomogenitasan data dari kedua kelompok.Uji homogenitas dilakukan untuk mengetahui apakah varians-varians dari data hasi pretes pada kelas eksperimen dan kelas kontrol homogen atau tidak homogen. Digunakan uji-F pada taraf signifikan 5\% $(a=0,05)$ untuk menguji homogen atau tidak homogen data dalam penelitian ini. Hipotesis yang akan diuji adalah:

$$
\mathrm{H}_{\mathrm{o}}=\text { Nilai varians kedua data homogen }
$$


$\mathrm{H}_{1}=$ Nilai varians kedua data tidak homogen

Kriteria pengujian :

Jika $\mathrm{F}_{\text {hitung }}<\mathrm{F}_{\text {tabel }}$, maka $\mathrm{H}_{\mathrm{o}}$ diterima

Jika $\mathrm{F}_{\text {hitung }}>\mathrm{F}_{\text {tabel }}$, maka $\mathrm{H}_{\mathrm{o}}$ ditolak

Tabel 4.9 Hasil Uji Homogenitas Data Posttest Eksperimen dan Kontrol

\begin{tabular}{|l|l|l|l|l|l|l|}
\hline $\begin{array}{l}\text { Kelompok } \\
\text { Kelas }\end{array}$ & $\boldsymbol{N}$ & $\mathbf{D}$ & $\boldsymbol{S}^{2}$ & $\boldsymbol{F}_{\text {hitung }}$ & $\boldsymbol{F}_{\text {tabel }}$ & Keputusan \\
\hline Eksperimen & 30 & 29 & 474,55 & 0,056 & 3,35 & Homogen \\
\hline
\end{tabular}

\subsubsection{Uji Linieritas}

\subsubsection{Uji Linieritas Pretest dan Posttest Kelas Eksperimen (Model Group Investigation)}

Dari hasil perhitungan uji linearitas untuk pretest dan posttest kelas eksperimen diperoleh harga $F_{\text {hitung }}=2,044$. Digunakan uji-F pada taraf signifikan 5\% $(a=0,05)$ dan diperoleh $\mathrm{F}_{\text {tabel }}=2,64$. Hasilnya dapat dilihat pada tabel berikut:

Tabel 4.10 Hasil Pretest dan Posttest Uji-F Kelas Eksperimen

\begin{tabular}{|c|c|c|c|c|c|}
\hline $\begin{array}{c}\text { Sumber Variansi } \\
(\mathbf{S V})\end{array}$ & $\begin{array}{c}\text { derajad } \\
\text { kebebasan } \\
(\mathbf{d k})\end{array}$ & $\begin{array}{c}\text { Jumlah } \\
\text { Kuadrat } \\
(\mathbf{J K})\end{array}$ & $\begin{array}{c}\text { Rata-rata } \\
\text { Jumlah } \\
\text { Kuadrat } \\
(\mathbf{R J K})\end{array}$ & $\mathbf{F}_{\text {hitung }}$ & $\mathbf{F}_{\text {tabel }}$ \\
\hline Total & 30 & 246864 & & 2,64 \\
\hline Regresi (a) & 1 & 245888,53 & 245888,53 & \multicolumn{2}{|c|}{ Keterangan: } \\
Regresi (b|a) & 1 & 21,33 & 21,33 & $F_{\text {hitung }} \leq \mathrm{F}_{\text {tabel }}$ atau \\
Residu & 28 & 54869,86 & 1959,63 & $2,044 \leq 2,64$, maka \\
Tuna Cocok & 5 & 43872,007 & 8774,401 & data berpola Linear \\
Kesalahan (Error) & 23 & 98741,867 & 4293,125 & \\
\hline
\end{tabular}

\subsubsection{Linieritas Pretest dan Posttest Kelas Kontrol (Model Sinektik)}


Dari hasil perhitungan uji linearitas untuk pretest dan posttest kelas eksperimen diperoleh harga $\mathrm{F}_{\text {hitung }}=2,46$. Digunakan uji-F pada taraf signifikan $5 \%(a=0,05)$ dan diperoleh $\mathrm{F}_{\text {tabel }}=2,55$. Hasilnya dapat dilihat pada tabel berikut:

Tabel 4.11 Uji Linieritas Kelas Kontrol (Model Sinektik)

\begin{tabular}{|c|c|c|c|c|c|}
\hline $\begin{array}{c}\text { Sumber Variansi } \\
\text { (SV) }\end{array}$ & $\begin{array}{c}\text { derajad } \\
\text { kebebasan } \\
\text { (dk) }\end{array}$ & $\begin{array}{c}\text { Jumlah } \\
\text { Kuadrat } \\
\text { (JK) }\end{array}$ & $\begin{array}{c}\text { Rata-rata } \\
\text { Jumlah } \\
\text { Kuadrat } \\
\text { (RJK) }\end{array}$ & $\mathbf{F}_{\text {hitung }}$ & $\mathbf{F}_{\text {tabel }}$ \\
\hline Total & 30 & 189376 & & 2,46 & 2,55 \\
\hline Regresi (a) & 1 & 1856533,3 & 1856533,3 & \multirow{5}{*}{\multicolumn{2}{|c|}{$\begin{array}{c}\text { Keterangan: } \\
\mathrm{F}_{\text {hitung }} \leq \mathrm{F}_{\text {tabel }} \text { atau } \\
2,46 \leq 2,55 \text {,maka } \\
\text { data berpola Linear }\end{array}$}} \\
\hline Regresi (b|a) & 1 & 210,752 & 210,752 & & \\
\hline Residu & 28 & 1667368,1 & 59548,86 & & \\
\hline Tuna Cocok & 6 & 1580308,9 & 263384,81 & & \\
\hline Kesalahan (Error) & 22 & 87059,2 & 3957,24 & & \\
\hline
\end{tabular}

\subsubsection{Uji Linieritas Posstest Kelas Eksperimen dan Kelas Kontrol}

Dari hasil perhitungan uji linearitas untuk posttest kelas eksperimen dan kontrol diperoleh harga $\mathrm{F}_{\text {hitung }}=2,46$. Digunakan uji-F pada taraf signifikan $5 \%(\mathrm{a}=0,05)$ dan diperoleh $\mathrm{F}_{\text {tabel }}=2,55$. Hasilnya dapat dilihat pada tabel berikut:

Tabel 4.12 Uji Linieritas Posttest Kelas Eksperimen dan Posttest Kelas Kontrol

\begin{tabular}{|c|c|c|c|c|c|}
\hline $\begin{array}{c}\text { Sumber Variansi } \\
(\mathbf{S V})\end{array}$ & $\begin{array}{c}\text { derajad } \\
\text { kebebasan } \\
(\mathbf{d k})\end{array}$ & $\begin{array}{c}\text { Jumlah } \\
\text { Kuadrat } \\
(\mathbf{J K})\end{array}$ & $\begin{array}{c}\text { Rata-rata } \\
\text { Jumlah } \\
\text { Kuadrat } \\
(\mathbf{R J K})\end{array}$ & $\mathbf{F}_{\text {hitung }}$ & $\mathbf{F}_{\text {tabel }}$ \\
\hline Total & 30 & 246864 & & 2,35 & 2,49 \\
\hline Regresi (a) & 1 & 245888,53 & 245888,53 & \multicolumn{2}{|c|}{ Keterangan: } \\
Regresi (b|a) & 1 & 1,317 & 1,317 & \multirow{2}{*}{ F $_{\text {hitung }} \leq \mathrm{F}_{\text {tabel }}$ atau } \\
Residu & 28 & 974,15 & 34,791 & $2,45 \leq 2,49$, maka \\
Tuna Cocok & 7 & 60236,517 & 8605,217 & data berpola Linear \\
Kesalahan (Error) & 21 & 61210,667 & 2914,794 & \\
\hline
\end{tabular}


Lingua Rima: Jurnal Pendidikan Program Studi Bahasa dan Sastra Indonesia

Vol. 9 No. 1 Juli 2020

\subsection{Uji Hipotesis}

Hipotesis statistik-statistik untuk mengetahui ada tidaknya perbedaan nilai rata-rata siswa antara kelas yang diberi perlakuan dengan menggunakan kelas yang diberi perlakuan dengan menggunakan model pembelajaran model group investigation sebagai kelompok eksperimen dan model sinektik sebagai kelompok kontrol. Maka digunakan uji-t dua pihak . Hipotesis penelitian ini berbunyi

$\mathrm{H}_{\mathrm{a}}$ :

1. Terdapat pengaruh model pembelajaran group investigation terhadap keterampilan menulis teks beritasiswa kelas VIII SMP Negeri 17 Kota Serang.

2. Terdapat pengaruh model pembelajaran sinektik terhadap keterampilan menulis teks berita siswa siswa kelas VIIISMP Negeri 17 Kota Serang

3. Terdapat perbedaan yang signifikan dengan menggunakan model pembelajarangroup investigation dan sinektik terhadap keterampilan menulis teks berita siswa siswa kelas VIII SMP Negeri 17 Kota Serang.

$\mathrm{H}_{\mathrm{o}}$ :

1. Tidak terdapat pengaruh model pembelajaran group investigation terhadap keterampilan menulis teks beritasiswa kelas VIII SMP Negeri 17 Kota Serang.

2. Tidak terdapat pengaruh model pembelajaran sinektik terhadap keterampilan menulis teks berita siswa siswa kelas VIII SMP Negeri 17 Kota Serang.

3. Tidak terdapat perbedaan yang signifikan dengan menggunakan model pembelajaran group investigation dan sinektik terhadap keterampilan menulis teks berita siswa siswa kelas VIII SMP Negeri 17 Kota Serang.

Model statistik yang digunakan adalah.

1. $\mathrm{H}_{\mathrm{a}}: \mu_{1}>\mu_{2}$

$\mathrm{H}_{\mathrm{o}}: \mu_{1} \leq \mu_{2}$

2. $\mathrm{H}_{\mathrm{a}}: \mu_{1}>\mu_{2}$

$\mathrm{H}_{\mathrm{o}}: \mu_{1} \leq \mu_{2}$

3. $\mathrm{H}_{\mathrm{a}}=\mu 1=\mu 2$

$\mathrm{H}_{\mathrm{o}}=\mu 1 \neq \mu 2$

Keterampilan menulis merupakan keterampilan yang paling kompleks, jika dibandingkan dengan ketiga keterampilan lainnya yaitu, keterampilan menyimak, berbicara, membaca. 
Lingua Rima: Jurnal Pendidikan Program Studi Bahasa dan Sastra Indonesia

Vol. 9 No. 1 Juli 2020

Keterampilan menulis memerlukan latihan secara terus menerus agar menghasilkan tulisan yang baik. Penggunaan model pembelajaran Group Investigation dan Sinektik digunakan karena melihat masalah awal yakni siswa masih rendah dalam keterampilan menulis, terutama menulis teks berita.Penilaian dalam menulis teks berita siswa kelas VIII SMP Negeri 17 Kota Serang didasarkan oleh beberapa aspek yang terkandung dalam tulisan teks berita siswa kelas VIII, yaitu: (1) judul; (2) kelengkapan isi; (3) organisasi penulisan; (4) pengunaan EBI; dan (5) kerapihan penulisan.

Keterbatasan dalam penelitian ini berdasarkan pemilihan judul, peneliti hanya memilih dua macam model pembelajar an dari banyaknya jenis model pembelajaran. Peneliti hanya memilih model pembelajaran Group Investigation dan Sinektik.Selain itu keterbatasan penelitian yang tidak dapat dijangkau oleh peneliti adalah faktor eksternal yang ada pada siswa (kesehatan, faktor keluarga, latar belakang sosial) sehingga dapat memungkinkan menghambat atau mengurangi konsentrasi bahkan mengurangi semangat belajar siswa dalam mengikuti kegiatan belajar. Kemampuan pengetahuan awal yang telah dimiliki oleh siswa seperti kurangnya pemahaman tentang teks berita misalnya menentukan isi berita, struktur teks berita tidak jelas, dan kurang teliti dalam menggunakan ketepatan ejaan seperti tanda baca.Kemudian, sebagian siswa masih bingung menyusun isi teks berita secara faktual. Tetapi hal tersebut dapat diatasi karena peran guru sebagai fasilitator, seandainya jika ada siswa yang kemampuan pemahamannya masih rendah maka guru langsung memfasilitasi dengan membimbing siswa yang kesulitan.

\section{E. KESIMPULAN DAN SARAN}

Hasil perhitungan nilai $\mathrm{t}_{\text {tabel }}$ dengan $\mathrm{dk}=\mathrm{n}_{1}+\mathrm{n}_{2}-2=30+30-2=58, \mathrm{t}_{\text {tabel }}=2,002$ dan $\mathrm{t}_{\text {hitung }}=4,89$ dengan kriteria $-\mathrm{t}_{\text {tabel }}>\mathrm{t}_{\text {tabel }}>\mathrm{t}_{\text {hitung }}$ maka Ho ditolak dan jika $-\mathrm{t}_{\text {tabel }}>\mathrm{t}_{\text {tabel }}>\mathrm{t}_{\text {hitung }}$ maka Ha diterima dari hasil perhitungan yang didapatkan $-2,00<4,89<2,002$ maka sesuai dengan kriteria penguji $-\mathrm{t}_{\text {tabel }}>\mathrm{t}_{\text {tabel }}>\mathrm{t}_{\text {hitung }}$ maka Ha diterima. Artinya, terdapat perbedaan dalam penerapan model pembelajaran model Group Investigation dan model Sinektik terhadap keterampilan menulis teks berita siswa kelas VIII SMP Negeri 17 Kota Serang. Hal tersebut dapat disimpulkan berdasarkan data hasil pembelajaran yang memiliki peningkatan nilai posttest dikelas penerapan model Group Investigation yang memiliki selisih 12 point dengan nilai rata-rata yang menerapkan model Group Investigation dan kelas yang menerapkan model Sinektik 90,5 > 78,6. 
Lingua Rima: Jurnal Pendidikan Program Studi Bahasa dan Sastra Indonesia

Vol. 9 No. 1 Juli 2020

Saran yang disampaikan dalam penilitian ini adalah sebagai berikut. (1) Bagi guru Bahasa Indonesia di SMP Negeri 17 Kota Serang disarankan untuk menerapan model pembelajaran Group Investigation khususnya pada pembelajaran menulis teks berita. (2) Kepada peneliti lain, paparan yang terdapat dalam penelitian ini dapat dijadikan bahan dalam meneliti masalah yang sejenis dengan penelitian ini, karena peneliti yakin bahwa dalam penelitian ini masih ada beberapa hal yang belum dibahas dan terselesaikan. (3) Peneliti menyarankan kepada pengambil kebijakan (sekolah) agar dapat merekomendasikan manfaat hasil penelitian ini untuk meningkatkan keterampilan menulis teks berita siswa lain.

\section{DAFTAR PUSTAKA}

Amintaningsih. 2011. Peningkatan Keterampilan Menulis Cerita Pendek Berbasis KUI (Kisah, Unsur Intrinsik, dan Khayalan) Melalui Model Sinektik di Kelas X SMA Negeri 1 Pemalang. Lingua Didaktika. Universitas Negeri Padang. Volum 2 no 22011 hal 75-85 http://ejournal.unp.ac.id/index.php/linguadidaktika/article/view/1258

Mariyatun dan Fatmawati, Desi. 2019. Pengaruh Penggunaan Model Cooperative Learning Tipe Group Investigation (GI) terhadap Hasil Belajar IPS Terpadu Kelas VIII Semester Genap SMPYPI 1 Bandar Mataram Lampung Tengah T.P 2015/2016. Promosi:Jurnal Program Studi Pendidikan Ekonomi. Universitas Muhammadiyah $\begin{array}{lllllll}\text { Metro. } & \text { Vol } & 4 & \text { No } & 1 & 2016 & \text { Hal }\end{array}$ http://ojs.fkip.ummetro.ac.id/index.php/ekonomi/article/view/472

Sutikno. 2016. Pengembangan Model Sinektik pada Pembelajaran Menulis Puisi Berkonteks Multikultural dalam Pembentukan Karakter Siswa SMA. Jurnal ILE\&L. IAIN $\begin{array}{llllllll}\text { Syekhnurjati. } & \text { Vol } & 1 & \text { No } & 2 & 2016 & \text { Hal }\end{array}$ http://www.syekhnurjati.ac.id/jurnal/index.php/jeill/article/view/225

Tarigan, Henri Guntur. 2008. Menulis Sebagai Suatu Keterampilan Berbahasa. Bandung: Angkasa

Krisbiono, Agung Dias; Supriyanti, Teguh; dan Rustono. 2016. Keefektifan Penggunaan Model Sinektik dan Model Simulasi dalam Pembelajaran Menulis Teks Drama Berdasarkan Gaya Belajar pada Peserta Didik Kelas XI SMA. Seloka. Universitas Negeri Semarang. $\begin{array}{llllll}\text { Vol } & 4 & \text { No } & 2 & 2015 & \text { hal }\end{array}$ https://journal.unnes.ac.id/sju/index.php/seloka/article/view/9870 